Revistade
Economila
Contemporâned

\title{
EFEITOS DA FLUTUAÇÃO DOS PREÇOS DAS COMMODITIES NO FLUXO DE INVESTIMENTO ESTRANGEIRO DIRETO NO BRASIL
}

\author{
Pedro Frizo ${ }^{a}$ \\ Roberto Arruda de Souza Lima ${ }^{b}$

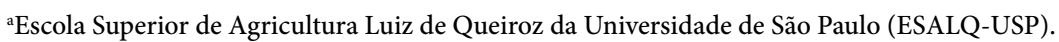

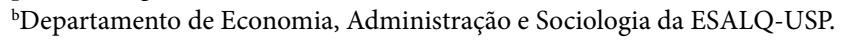

Artigo recebido em 10/02/2014 e aprovado em 16/01/2015.

RESUMO: Dada a predominância das commodities na pauta de exportações brasileira, este trabalho verificou qual a relação entre a flutuação dos preços internacionais dos bens primários e o fluxo de investimento estrangeiro direto, financiador principal do déficit estrutural da conta corrente. A partir do pressuposto da nova economia do desenvolvimento, onde a entrada de investimento estrangeiro direto depende da razão dívida externa/exportações, foi construído um modelo onde esta medida de risco é uma função do preço internacional das commodities e da taxa de câmbio (dólar/real). Utilizou-se a taxa de substituição de poupanças como variável dummy na construção do modelo. Os resultados demonstraram que os preços internacionais possuem significativa relação negativa com o indicador de risco utilizado, evidenciando a importância dos bens primários no financiamento da conta corrente e, por consequência, no saldo final do balanço de pagamentos.

PALAVRAS-CHAVE: Câmbio; commodities; preços internacionais; risco da dívida.

CLASSIFICAÇÃO JEL: F14; F21; F34.

\footnotetext{
Correspondência para Pedro Frizo.

a E-mail: pedro.frizo@gmail.com.
} 


\section{THE EFFECTS OF THE COMMODITIES PRICES FLUCTUATION ON THE FOREIGN DIRECT INVESTMENT FLOW IN BRAZIL}

ABSTRACT: Given the commodities predominance on Brazilian exports, this research examined the relationship between the international prices of commodities and foreign investment inflow, which is the main funding source of the structural current account deficit. Based on the new development economics axiom, which holds that the foreign investment inflow depends on the external debt/exports ratio, a model was developed where this risk measure is a function of the international prices of commodities and the exchange rate (dollar/real). The savings substitution rate was employed as a dummy variable in the model. The results demonstrated that international prices have a significantly negative relationship with the risk measure, which is evidence of the relevance of the primary goods in funding the current account and, consequently, the balance of payments.

KEYWORDS: Exchange rate; commodities; international prices; debt risk.

\section{INTRODUÇÃO}

A nova economia do desenvolvimento, ou a chamada nova macroeconomia desenvolvimentista, levanta uma série de questões contra a ortodoxia convencional. Podemos destacar, entre elas, a crítica em relação à poupança externa ${ }^{1}$ como fonte de financiamento para a formação bruta de capital fixo (FBKF) em uma economia.

Bresser-Pereira (2007) é um dos autores mais conhecidos que discorre sobre as diferenças de um país financiar seus investimentos via poupança interna ou através de déficits em conta corrente, definido pela literatura como poupança externa. Para o autor, a diferença principal entre as duas formas de poupança reside nas consequências para a taxa de câmbio.

Segundo o autor, uma entrada maciça de moeda estrangeira na economia gera sobrevalorização cambial advinda de constantes déficits em conta corrente. A consequência direta desse comportamento reside sobre os salários reais (aumentam em caso de apreciação do real), impulsionando o consumo privado, uma vez que os bens comercializáveis importados apresentam redução em seus respectivos preços.

Tal comportamento também afeta diretamente a taxa de lucro das indústrias, uma vez que a apreciação cambial reduz as exportações. Além disso, o setor industrial como um todo adquire expectativas negativas, uma vez que há uma projeção de lucros menores para os próximos períodos e diminuição do volume exportado, reduzindo o ní vel de investimento como um todo. Há, portanto, em uma economia baseada no financiamento externo, um trade-off entre consumo e investimento.

Tais observações constatam a importância das contas nacionais no processo de investimento e, consequentemente, no crescimento econômico.

Tendo isso em mente, procurou-se identificar quais as variáveis-chave na composição da conta corrente brasileira. Sabendo que a conta corrente é resultado da balança comercial somado aos rendimentos líquidos enviados ao exterior (Bacha e Lima, 2009), buscou-se identificar os produtos de maior peso na composição das contas externas.

Segundo dados da Secretaria de Comércio Exterior do Ministério do Desenvolvimento, Indústria e Comércio Exterior (SECEX), em 2011, 54\% das exportações foram bens primários. Isso demonstra relativo peso dessa categoria de bens sobre a balança comercial e, consequentemente, sobre o saldo em conta corrente. Uma vez que os bens 
primários apresentam uma alta variabilidade de seus preços internacionais ${ }^{2}$, o presente trabalho procurou captar os efeitos das mudanças nos preços das principais commodities exportadas pelo Brasil no fluxo de investimento estrangeiro direto (IED). $\mathrm{Na}$ seção 2 consta a revisão de literatura, na seção 3 a metodologia utilizada e nasseções 4 e 5 constam os resultados e as considerações finais, respectivamente.

\section{REVISÃO DE LITERATURA}

Feijó e Ramos (2008) determinam o saldo da conta corrente através da ótica da poupança interna e da poupança externa. Segundo eles, um déficit em conta significa uma poupança externa positiva, ou seja, um excesso de investimento externo em relação à poupança doméstica. O contrário, um superávit na conta corrente, corresponde a uma poupança externa negativa.

Diversos trabalhos foram elaborados com o intuito de estimar a taxa de substituição entre poupança interna e poupança externa (Fry, 1978; Edwards, 1995; Schmidt-Hebel, 1992; Feldstein e Horioka, 1980). Destaque para Uthoff e Titelman (1998), que procuraram estimar os determinantes da poupança interna para os países latino-americanos, entre 1972 e 1993.

Da mesma forma como os autores acima, Bresser-Pereira (2007) buscou compreender a dinâmica do processo de substituição das poupanças no Brasil da década de 1990. O autor encontrou uma taxa de substituição semelhante à encontrada na literatura - uma média de aproximadamente 0,5 (em uma escala de 0 a 1 , onde 0 significa complementação plena e 1 a substituição plena) - levantando importantes questões sobre a dinâmica dos investimentos privados no Brasil neste período.

Bresser-Pereira (2007) levantou que no período de 1993 até 1999, quando houve um aumento expressivo no déficit da conta corrente, os investimentos obtiveram uma queda significativa. No período compreendido entre os anos 2000 e 2005, quando constantes superávits são auferidos na conta corrente, a formação bruta de capital fixo cresceu ligeiramente.

De maneira contrária, Arend e Fonseca (2012) criticam a formulação dos desenvolvimentistas a partir de uma visão neoschumpeteriana sobre a relação entre FBKF e a entrada de capital estrangeiro. Baseado em Perez (2004), os autores discorrem sobre a importância do capital estrangeiro para os países periféricos como forma de inclusão

2 Em Sinott, Nash e De la Torre (2010)encontram-se exemplos significativos da maior variabilidade dos preços das commodities em relação aos produtos manufaturados. desses no paradigma tecnológico vigente. A consequência direta são taxas de crescimento do PIB maiores, advinda dos ganhos de produtividade.

Para esses dois autores schumpeterianos, o capital estrangeiro somente trará menores taxas de crescimento quando caracterizar-se em capital especulativo e não capital produtivo. Geralmente tal fato ocorre em períodos, segundo Arend e Fonseca (2012), de instalação de um novo paradigma tecnológico nos países desenvolvidos. É neste momento que a entrada de capitais externos trará as consequências para a economia postuladas anteriormente pelos desenvolvimentistas. A Figura 1, apresentada a seguir, foi retirada de Arend e Fonseca (2012) e consiste em seu principal argumento contra o conceito de substituição de poupanças, mostrando que este processo ocorre somente para um determinado período de tempo, não se aplicando à série toda.

Figura1 - Brasil: Evolução da poupança interna e da poupança externa, no período de 1955 a 2006 (em bilhões de dólares)

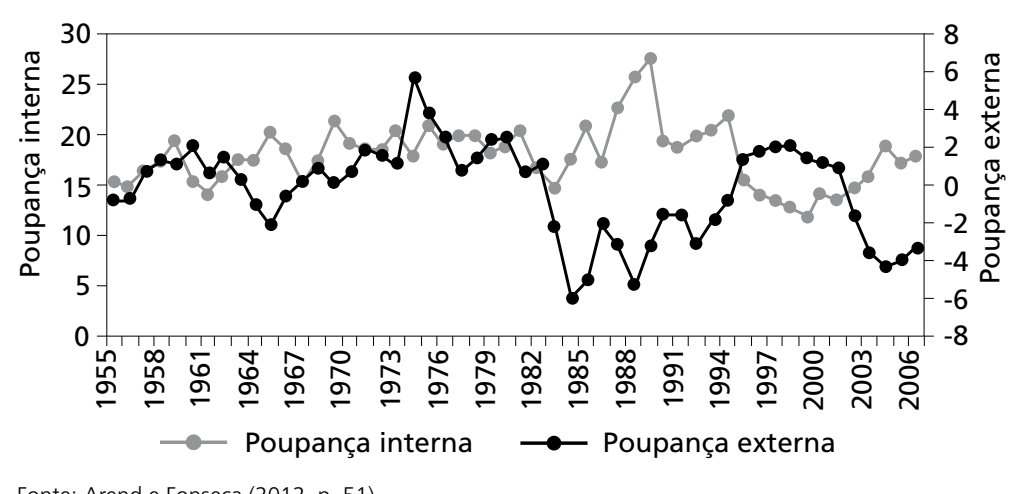

Fonte: Arend e Fonseca (2012, p. 51).

Entretanto, há dois fatores sobre a economia brasileira que devem ser considerados e que contrariam as conclusões obtidas em Arend e Fonseca (2012). O primeiro fator refere-se à conjuntura industrial e ao volume de entrada de capital estrangeiro na economia brasileira entre 1970 até 1990. Em seu modelo sobre substituição de poupança, Bresser-Pereira (2007) ressalta que há determinados momentos onde o financiamento com poupança externa poderá ser destinado ao investimento e não ao consumo. Entretanto, isso ocorrerá somente em períodos onde o patamar da taxa esperada de lucro dos investimentos incentiva os empresários a direcionarem os recursos à produção. Hermann (2005) aponta a alta capacidade ociosa da indústria brasileira durante o milagre, devido ao ajuste recessivo tomado pelo Plano de Ação Econômica do Governo (PAEG) de 1964 até 1966. Logo, esta capacidade ociosa pode ter sido um atrativo ao capital estrangeiro, direcionando tais recursos aos investimentos e não ao consumo. 
Um segundo item a ser ressaltado é o volume de capital estrangeiro entrante na indústria de ponta tecnológica. Como demonstra a Figura 2, o volume bruto de investimento nessa indústria cresceu significativamente após a segunda metade da década de 1990. Isso evidencia que a análise feita em Arend e Fonseca (2012) sobre os ciclos de IED produtivo apresenta certas restrições, pois o aumento no investimento bruto na indústria de ponta tecnológica não aumentou a FBKF brasileira e tampouco impediu o comportamento inverso entre a poupança externa e interna.

\section{Figura2 - Entrada de IED bruto nas indústrias de ponta (eletro/eletrônico} e telecomunicações, em bilhões de dólares de 2005)

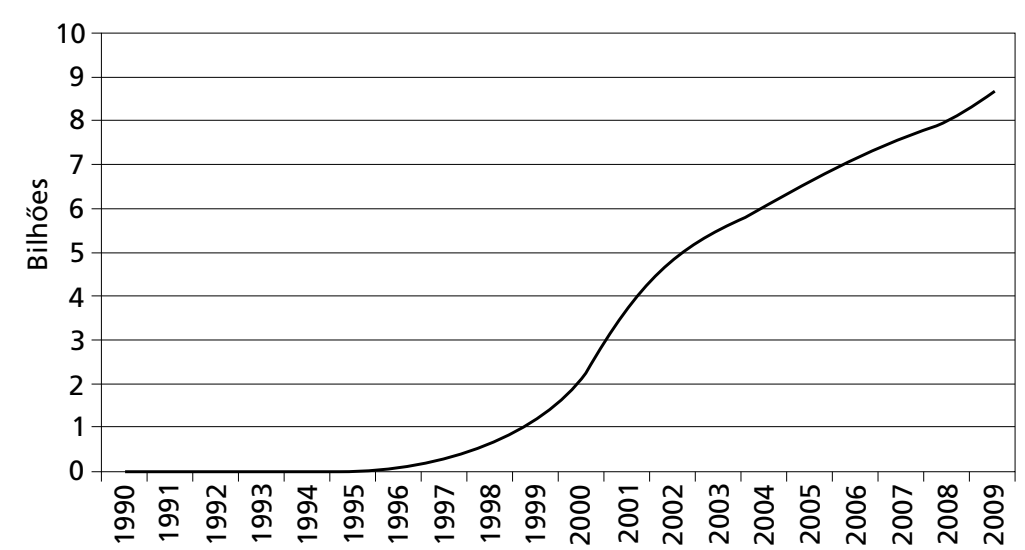

Nota: Arend e Fonseca (2012) determinam a indústria eletro/eletrônico como o setor industrial mais tecnológico atualmente.

Fole: Elaboraca propra com base em dados do Banco Central (2013).

Por isso, adotar o modelo de ciclos de inovação como explicação para a FBKF pode gerar resultados enviesados, principalmente no cenário atual de alta fluidez do capital financeiro internacional. De fato, como levanta Vernon $(1979)^{3}$ e Guillén e Garcia-Canal (2009), a teoria do ciclo do produto está, em grande parte, defasada. A acentuação da globalização fez com que a defasagem de inovação entre as nações reduzisse significativamente, em sua maioria explicada pela numerosa presença de filiais de multinacionais em um grande número de países, e de muitas multinacionais advindas de nações emergentes atuando em diversos países do mundo, inclusive nas nações desenvolvidas.

3 Vernon (1966) é um dos trabalhos que construíram a teoria do ciclo do produto. Esta teoria, posteriormente, seria utilizada por economistas neoschumpeterianos para a explicação do padrão de comércio internacional e transferência tecnológica. Esta teoria também foi a base para o trabalho de Perez (2004).
Logo, a baixa taxa de poupança interna brasileira, recorrentemente tida como um dos principais motivos da baixa FBKF, responderá à dinâmica do IED no Brasil. Uma entrada maior de investimento estrangeiro significa um aumento de oferta de divisas (I), valorizando o câmbio real/dólar (II). Essa valorização aumentará as importações e diminuirá as exportações (III), evidenciando a tendência estrutural da economia brasileira em auferir déficits nas transações correntes (IV), dado também que a saída de renda e serviços aumentará devido ao fluxo maior de IED. Este déficit em transações correntes poderá ser financiado por mais IED. A Figura 3 ilustra a relação negativa entre as transações correntes e o IED no Brasil, em dólares de 2005.

\section{Figura 3 - Saldo das transações correntes e fluxo de IED (em dólares de 2005)}

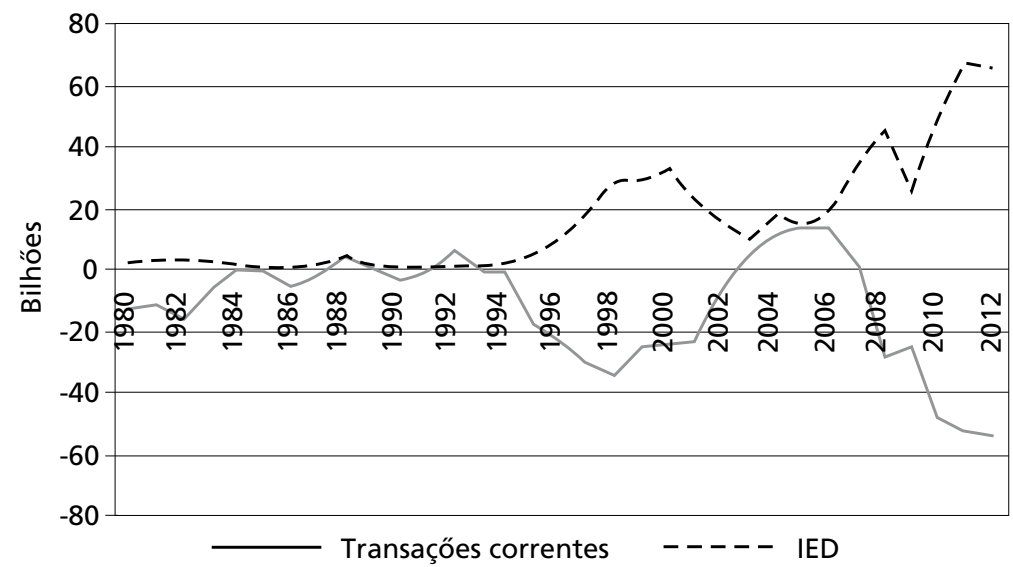

Fonte: Elaboração própria com base em dados do Banco Central (2013).

Entretanto, um valor demasiado altoda dívida externa em relação às exportações - ocasionado pela perda da competitividade dos produtos brasileiros no mercado internacional e pelo aumento dos compromissos externos - poderá diminuir a atração brasileira aos recursos externos ${ }^{4}$, levando a uma crise no balanço de pagamentos. Esta crise levará a uma depreciação do real frente ao dólar, incentivando as exportações e diminuindo as importações, fazendo com que a razão divida externa/exportações volte a cair. Logo, o fluxo de IED é fundamental para a compreensão do saldo final das transações correntes e sua dinâmica particular.

Como constatado no começo do trabalho, os bens primários possuem grande importância na composição da balança comercial. Negri e Alvarenga (2011) ressaltam o

${ }_{4}$ Bresser-Pereira (2007) utiliza a razão dívida externa/exportações como indicador principal dos investidores externos na avaliação do risco de investimento. 
recente comportamento da pauta das exportações brasileiras, onde as commodities representavam 51\% do total exportado em 2010. De acordo com dados da SECEX, em 2011, ao se comparar o total de commodities exportadas com o total exportado, encontrou-se uma participação de $54 \%$ dos produtos primários sobre a pauta de exportações.

A composição da pauta de exportações evidencia a relevância das commodities sob a determinação do saldo final das contas externas. A literatura existente ${ }^{5}$ discorre a respeito dos riscos envolvendo as flutuações nos preços das commodities, uma vez que tais produtos apresentam uma variabilidade maior de seus preços se comparado aos bens industrializados. Com isso, as próximas seções tratarão de se aprofundarem os efeitos dos preços das commodities na razão dívida externa/exportações, indicador fundamental para a compreensão do fluxo de IED.

\section{METODOLOGIA}

A identificação dos efeitos dos ciclos de preços das principais commodities exportadas pelo Brasil na relação dívida externa/exportação e, consequentemente, na dinâmica do saldo das transações correntes, será obtida através de um modelo de regressão linear múltipla. No entanto, como será explicado no decorrer deste trabalho, utilizar-se-á o grau de substituição entre poupança interna e externa como dummy para a construção do modelo. A metodologia utilizada será a positivista lógica, sendo o método aplicado a regressão linear múltipla, utilizando o software estatístico R 2.13 .

A construção do modelo começa a partir de uma situação, ceterisparibus, onde se assume que a conta "rendas e serviços" terá valor constante no saldo em transações correntes. Na prática, observam-se para o período analisado (de 1996 até 2011) mudanças nessa subconta, uma vez que esta responde proporcionalmente à entrada de IED. No entanto, essa subconta não possui o mesmo peso se comparada às exportações e importações, sendo essas duas subcontas as mais relevantes para determinação do saldo das transações corrente, conforme demonstra a Tabela 1.

Tabela 1 - Razão entre a subconta e o PIB (média de 1996 a 2011)

\begin{tabular}{ccc}
\hline Exportaçôes & Importaçoes & Serviços e Rendas \\
\hline $10 \%$ & $-8 \%$ & $-3 \%$ \\
\hline
\end{tabular}

Fonte: Elaboração própria com base em dados do Banco Central (2013).
Na construção do modelo também se assume que o quantum exportado depende diretamente da taxa de câmbio real/dólar, ou seja, da competitividade dos produtos brasileiros no mercado externo.

Como foi definido por Feijó e Ramos (2008), o saldo em transações correntes é igual ao saldo da balança comercial, somado ao saldo de serviços e rendas e às transferências unilaterais. Ou seja,

$$
T C=(X-M)+R L E
$$

Na equação (1), $X$ representa as exportações; $M$, as importações; e $R L E$, as rendas líquidas enviadas ao exterior. Logo, assumimos que a balança comercial $(B C=X-M)$ será determinada pelos preços das commodities e pela taxa de câmbio. Esta última sofrerá significativa influencia do fluxo de investimento estrangeiro direto. Como já foi mencionado anteriormente, uma entrada crescente de IED significará uma maior oferta de divisas, levando a um aumento da importação e do consumo. Isto gerará uma tendência a obter saldo negativos nas transações correntes (poupança externa) e a diminuir os investimentos.

$$
\begin{aligned}
& B C=B C\left(\lambda . P_{E}\right) \\
& \frac{\partial \lambda}{\partial I E D}<0 \text { e } \frac{\partial B C}{\partial I E D}<0 .
\end{aligned}
$$

Em (2), $P_{e}$ são os preços de exportação das commodities e $\lambda$ é a taxa de câmbio. O IED financia o déficit em transações correntes e valoriza a taxa de câmbio concomitantemente. Segundo Bresser-Pereira (2007), a função consumo é definida pela renda nacional e pelo custo de oportunidade de investimento, dado pelos lucros subtraídos pela taxa de juros.

$$
C=C\left(R_{n^{\prime}}(\pi-\mathrm{i})\right)
$$

Em (3), $R_{n}$ é a renda nacional, $\pi$ é a taxa de lucro e $i$, a taxa de juros. Dado um nível constante de salários, teremos que a renda nacional varia no curto prazo de acordo com a taxa de câmbio. Em uma economia com a taxa de câmbio flutuante e recebedora de IED, um fluxo maior de investimento estrangeiro significará uma valorização da taxa de câmbio, aumentando o poder de compra dos trabalhadores e, consequentemente, o consumo em detrimento do investimento, já que consumo e poupança interna possuem uma relação negativa.

$$
C=C(\lambda,(\pi-i)
$$

\footnotetext{
5 Veja Sinnott et al. (2010) e Lederman, Mengistae e Xu (2010).
}

$$
C=C\left(I E D, P_{E^{\prime}}(\pi-i)\right)
$$


De (4) e (5), temos as seguintes relações:

$$
\frac{\partial C}{\partial I E D}>0 ; \frac{\partial C}{\partial P_{E}}>0 ; \frac{\partial C}{\partial(\pi-i)}<0
$$

Para que seja captada a influência dos ciclos dos preços das commodities na dinâmica das transações correntes no Brasil, deve-se identificar a relação entre os preços desses produtos com a entrada de IED.

A entrada e a saída de IED, para o autor, são cruciais no entendimento das crises cíclicas no balanço de pagamentos brasileiro. Dada a recorrente entrada de poupança externa, a valorização cambial diminui o saldo da balança comercial, gerando déficits na transação corrente. Logo, uma das finalidades do IED é financiar estes déficits. Entretanto, a partir do momento em que o risco de investimento - dado pela proporção dívida externa/exportações - é elevado, há uma interrupção do fluxo de IED, gerando significativa desvalorização cambial e crise no balanço de pagamentos. Com isso, temos que o fluxo de IED é determinado pelo grau de risco (dado pela razão dívida externa/exportações) ${ }^{6}$. Logo,

$$
I E D=I E D\left(\frac{D e}{E}\right)
$$

Em (6), $D_{\mathrm{e}}$ é a dívida externa, $E$ são as exportações e a razão de ambos é uma proxy para o risco-país. A exportação dependerá diretamente do preço de exportação das commodities e da taxa de câmbio. Logo, podemos modificara expressão (6) para:

$$
I E D=I E D\left(\frac{D e}{P_{E}, \lambda}\right)
$$

Com isso, o modelo nos diz que o financiamento do déficit estrutural das transações correntes brasileiras depende do preço pago pelas commodities, uma vez que um volume financeiro maior das exportações brasileiras diminuirá a percepção de risco dos investidores estrangeiros, prolongando o período de tempo em que o saldo deficitário das transações correntes será financiado pelo IED. Logo, pode-se afirmar, segundo o modelo desenhado, que a entrada de recursos externos depende diretamente do preço pago ao exportador brasileiro de commodities e da taxa de câmbio.

Como é demonstrado pela equação (5), o consumo depende da entrada de IED, do preço de exportação $\left(P_{\mathrm{E}}\right)$ e do custo de oportunidade de investimento $(\pi-i)$. Sabemos

6 Outros determinantes além da percepção de risco podem ser encontrados em Agarwal (1980), Nunnenkamp (2002) e Stevens (1994). Para o caso brasileiro ver Laplane e Sarti (1997) e Nonnenberg (2003). que o consumo e a poupança externa possuem relação negativa com a poupança interna e a FBKF. A política econômica ideal, segundo Bresser-Pereira (2007), seria aquela que promovesse o investimento com recursos internos e não externos. Logo receber significativos fluxos de IED e ter o saldo de transações correntes vulneráveis aos preços das commodities fazem com que haja redução no investimento total na economia e aumento do consumo. Isso leva, no médio prazo, ao deterioramento das transações correntes e a uma possível crise no balanço de pagamentos.

Entretanto, há de considerar que o custo de oportunidade de investimento $(\pi-i)$ é determinante direto da taxa de substituição de poupança. Como afirma Bresser-Pereira (2007), quando as oportunidades de lucro são favoráveis, o aumento da renda nacional é direcionado ao investimento e não ao consumo. Logo, este trabalho utilizará a taxa de substituição entre poupança externa e interna como dummy, uma vez que, para valores pequenos, os preços das commodities terão um impacto menos acentuado sobre a razão dívida externa/exportações. Isso ocorre devido ao fato de que os recursos externos serão direcionados ao investimento e à promoção das exportações, reduzindo a importância das commodities em equilibrar o saldo das transações correntes.

\section{RESULTADOS}

Na Tabela 2 consta um resumo da série de dados utilizada no modelo econométrico proposto. Esta série de dados contém o índice de endividamento externo dividido pelas exportações, o índice logaritmo dos preços de exportação dos produtos agrícolas e minérios, e, por fim, a taxa de câmbio real/dólar tendo o ano de 2005 como o ano-base.

Tabela 2 - Resumo dos dados utilizados

\begin{tabular}{lcccc}
\hline \multicolumn{5}{c}{ Varíaeis utlizadas no modelo } \\
\hline Valor & Endividamento & Agrícola & Minério & Câmbio \\
\hline Mínimo & 1,33 & 1,81 & 1,91 & 1,54 \\
$1^{\circ}$ quartil & 2,95 & 1,88 & 1,99 & 2,06 \\
Mediana & 3,77 & 1,93 & 2,5 & 3,16 \\
Média & 3,34 & 1,95 & 2,08 & 3,41 \\
$3^{\circ}$ quartil & 3,97 & 1,98 & 2,12 & 4,59 \\
Máximo & 5,03 & 2,23 & 2,48 & 6,40 \\
\hline
\end{tabular}

Fonte: Elaboração própria com base em dados do Ipeadata (2012).

A partir dos dados utilizados percebe-se que os preços internacionais de exportação de minério foram ligeiramente maiores do que os preços agrícolas. A Figura 4 apresenta a evolução logarítmica dos preços internacionais, ilustrando a variação maior do preço para os minérios. 
Figura 4 - Evolução logarítmica do índice dos preços de exportação brasileira de commodities

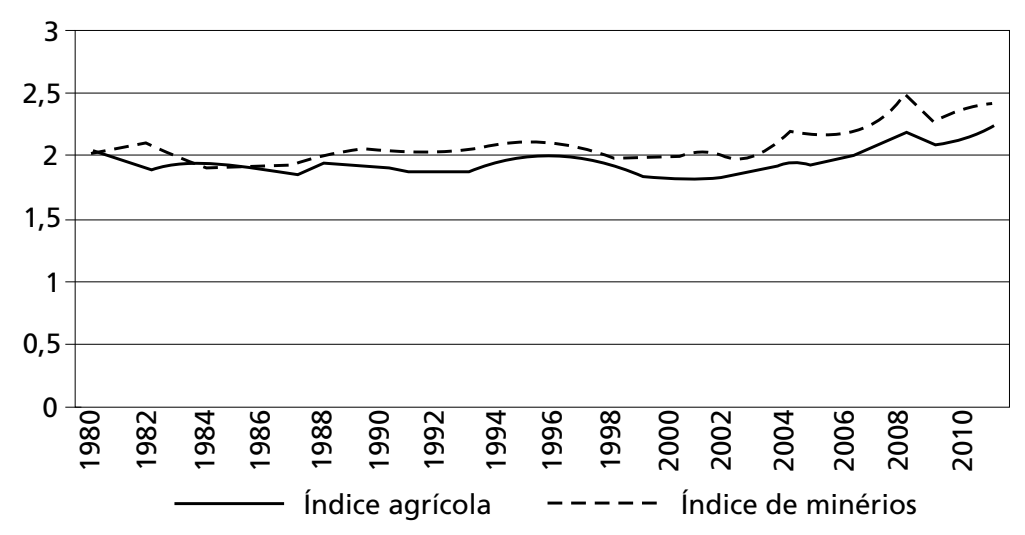

Fonte: Elaboração própria com base em dados do Ipeadata (2012).

No entanto, como explica o modelo teórico proposto, o aumento no nível dos preços internacionais das commodities terá impacto menor sobre a razão dívida externa/ exportações em períodos de baixa taxa de substituição entre as poupanças externa e interna. Segundo os autores da nova economia do desenvolvimento isso ocorrerá quando a taxa esperada de lucro for alta a ponto de incentivar os empresários a investirem ao invés de consumirem. Logo, utilizou-se a taxa de substituição de poupanças como dummy para captar essa dinâmica no período de tempo estudado. A Figura 5 ilustra o valor da taxa de substituição entre poupanças, de 1981 até 2011.

Figura 5 - Taxa de substituição entre a poupança externa e interna

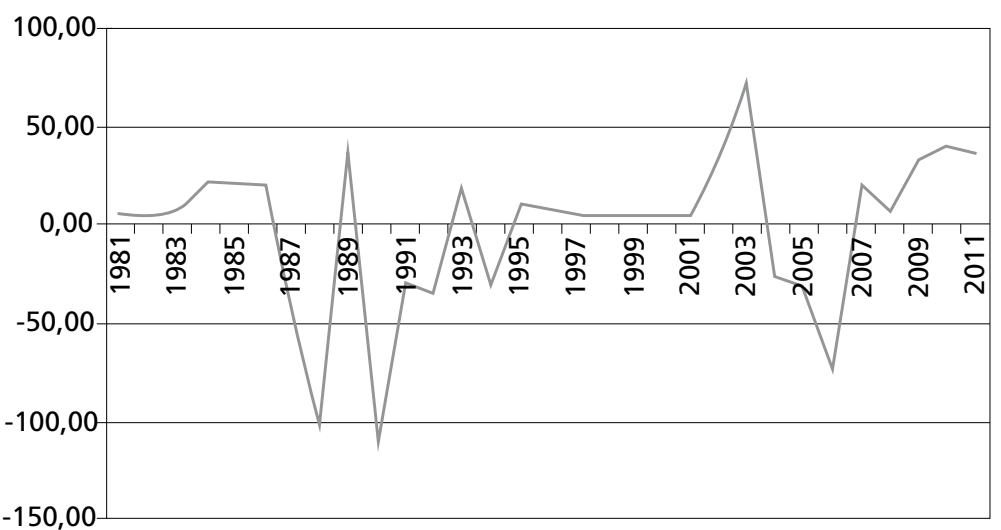

Fonte: Elaboração própria com base em dados do Banco Central e Banco Mundial (2013).
Como se observa, em poucas situações a taxa de substituição de poupança situa-se entre -10 e 10, demonstrando que na maioria das vezes a entrada de recursos externo diminui a propensão a poupar, dado o aumento da renda nacional. Para taxas de substituição entre -10 e 10, a variável dummy teria valor igual a 1, enquanto que para outras taxas maiores que 10 e menores que -10 a variável dummy teria valor igual a 0 .

Os resultados do modelo econométrico são apresentados na Tabela 3. Conforme esperado, os valores obtidos são condizentes com os resultados do modelo teórico desenvolvido na seção anterior. Os preços agrícolas e minerais, principalmente este último, demonstraram o comportamento esperado em relação à razão dívida externa/ exportações.

\begin{tabular}{lrrrl}
\multicolumn{5}{c}{ Tabela 3 - Resultados da regressão linear } \\
\hline \multicolumn{5}{c}{ Valor Estimado Erro padrão Valor-t Pr(>?t?) } \\
\hline (Intercepto) & 1,742 & 244,476 & 7,126 & $1,16 \mathrm{E}-07$ \\
Agrícola & $-0,899$ & 192,408 & $-0,467$ & 0,644 \\
Mineral & $-592,717$ & 175,746 & $-3,373$ & 0,002 \\
Câmbio & $-0,036$ & 0,103 & $-0,357$ & 0,723 \\
Z2 & 0,502 & 0,221 & 2,282 & 0,031 \\
$\mathrm{R}^{2}$ & & & 0,78 \\
\hline
\end{tabular}

Fonte: Elaboração própria com base nos resultados da pesquisa.

Apenas o índice mineral e a variável dummy demonstraram ser significativos. Os índices de preços de exportação das commodities selecionadas apresentaram coeficientes negativos, assim como a taxa de câmbio. Ou seja, desvalorizações cambiais e aumento nos preços das commodities equilibram o saldo das transações correntes, uma vez que aumentam o fluxo de IED no Brasil e reduzem a percepção de risco por parte dos investidores externos. O $R^{2}$ obtido de 0,78 demonstra que o modelo proposto possui um poder de explicação satisfatório para o comportamento da razão dívida externa/exportações.

Os resultados obtidos com o modelo demonstram a eficácia de aumentos dos preços das commodities em financiar o déficit estrutural da balança comercial brasileira. Portanto, constata-se que os preços das commodities exercem significativa influência em manter o ritmo de entrada de investimento estrangeiro, financiando o déficit estrutural. Entretanto, quedas nos valores internacionais destes produtos tendem a acentuar o déficit das transações correntes, aumentando o risco e diminuindo no médio prazo a entrada de investimento estrangeiro, o que levaria a uma crise no balanço de pagamentos.

\section{CONSIDERAÇÕES FINAIS}

O presente trabalho teve como objetivo principal identificar se os preços de exportação das principais commodities exportadas pelo Brasil influenciam na dinâmica dos investimentos estrangeiros e do saldo da balança de pagamentos. Por serem produtos 
de variabilidade maior do que os bens industrializados, a hipótese inicial é de que as variações no curto prazo nos preços de exportação das commodities afetam o saldo final das transações correntes e a percepção de risco dos investidores externos, interferindo, consequentemente, na entrada de investimento estrangeiro direto.

Conclui-se que basear a maioria da pauta de exportações em produtos primários apresenta a suas vantagens e desvantagens. Em momentos de crescimento econômico mundial, o Brasil pode usufruir de aumentos nos preços de exportação, financiando os déficits estruturais das transações correntes. Entretanto, a primarização das exportações faz com que a razão dívida externa/exportação - tomada como medida de risco pelos investidores internacionais - seja demasiadamente suscetível aos preços desses bens, os quais, segundo a literatura, são mais voláteis se comparados aos bens manufaturados. Novas pesquisas que busquem analisar o canal de distribuição entre as variações nos preços internacionais das commodities e a determinação do consumo e investimento colaborarão para aprimorar o modelo descrito neste trabalho.

\section{REFERÊNCIAS BIBLIOGRÁFICAS}

AGARWAL, J. Determinants of foreign investment: a survey. Weltwirtschaftliches Archiv, v. 116, n. 4, p. 739-773, dez. 1980

AREND, M; FONSECA, P. C.D. Brasil (1955-2005): 25 anos de catching up, 25 anos de falling behind. Revista de Economia Política, São Paulo, v. 32, n. 1, p. 33-54, 2012.

BACHA, C. J. C; LIMA, R. A. S. Macroeconomia. Campinas: Editora Alinea, 2009.

BANCO CENTRAL DO BRASIL. Câmbio e capitais internacionais. [On-line] BCB. Disponível em:<www.bcb.gov.br>. Acesso em: 01 abr. 2013 .

BANCO MUNDIAL. [On-line] Banco Mundial. Disponível em: <www.worldbank.org $>$. Acesso em: 01 abr. 2013.

BARBOSA, A. L. S. O capital se faz em casa. Rio de Janeiro: Paz e Terra, 1973.

BRESSER-PEREIRA, L. C. "Substituiç̃o de poupanças". In: BRESSER-PEREIRA, L. C. Macroeconomia da estagnação: crítica da ortodoxia convencional no Brasil pós-1994. São Paulo: Editora 34, 2007, p. 149-166.

COHEN, D. "Growth and external debt”. In: DER PLOEG, F. V. (Ed.) The handbook of international macroeconomics. Londres: Basil Blackwell, 1994.

EDWARDS, S. Why are saving rates so different across countries? An international comparative analysis. NBER Working Papers Series, n. 5097, 1995.

FEIJÓ, C. A; RAMOS, R. L. O. Contabilidade social. 3 ed. Rio de Janeiro: Editora Campus, 2008.

FELDSTEIN, M; HORIOKA, C. Domestic savings and international capital flows. Economic Journal, Royal Economic Society, v. 90, p. 314-328, 1980
FRY, M. J. Money and capital or financial deepening in economic development? Journal of Money, Credit and Banking, v. 10, n. 4, p. 464-475, 1978

GUILLÉN, M. F.; GARCÍA-CANAL, E. The American model of the multinational firm and the "new" multinationals from emerging economies. Academy Management Perspectives, v. 23, n. 2, p. 23-35, mai. 2009.

HERMANN, J. "Reformas, endividamento externo e o 'milagre' econômico (1964-1973)" In: GIAMBIAGI, F; VILLELLA, A.; BARROS DE CASTRO, L; HERMMAN, J. Economia brasileira e contemporânea (1945-2004). Rio de Janeiro: Editora Elsevier/Campus, 2005, p. 69-92.

INSTITUTO DE PESQUISA ECONOMICA APLICADA. IPEADATA. Disponível em: <www. ipeadata.gov.br>. Acesso em: 01 dez. 2012.

LAPLANE, M. F.; SARTI, F. Investimento Direto Estrangeiro e a retomada do crescimento sustentado nos anos 90. Economia e Sociedade, Campinas, v. 8, p. 143-181, jun. 1997.

LEDERMAN, D; MENGISTAE, T.; XU, C. Microeconomic consequences and macroeconomic causes of foreign direct investment in southern African economies. Policy Research Working Paper Series, Banco Mundial, n. 5416, 2009.

MINISTÉRIO DO DESENVOLVIMENTO, INDÚSTRIA E COMÉRCIO EXTERIOR (MDIC). [On-line] MDIC. Disponível em: <http://www.desenvolvimento.gov.br/sitio/>. Acesso em: 01 nov. 2012

NEGRI, F.; ALVARENGA, G. V. A primarização da pauta de exportações no Brasil: ainda um dilema. In: IPEA (Org.) Radar: tecnologia, produção e comércio exterior. Brasília: IPEA, 2011

NONNENBERG, M. J. B. Determinantes dos investimentos externos e impactos das empresas multinacionais no Brasil - As décadas de 1970 e 1990. Texto para Discussão, IPEA, Rio de Janeiro, n. 969, ago. 2003

NUNNENKAMP, P. Determinants of FDI in developing countries: has globalization changed the rules of the game? Kieler Arbeitspapiere, n. 1122

PEREZ, C. "Revoluciones tecnológicas y paradigmas tecnoeconómicos". In: PEREZ, C. Revoluciones tecnológicas y capital financiero. México D.F: XXI Editores, 2004, p. 32-64.

REINHART, C. M; TALVI, E.Capital flows and saving in Latin America and Asia: a reinterpretation. Journal of Development Economics, v. 57, n. 1, p. 45-66, 1998

SCHMIDT-HEBEL, K.; WEBB, S. B.; CORSETTI, G. Household saving in developing countries: first cross-country evidence. World Bank Economic Review, World Bank Group, v. 6, n. 3 , p. 529-547, set. 1992

SINNOTT, E; NASH, J: DE LA TORRE, A. Recursos naturais na América Latina: indo além dos altas e baixas. Rio de Janeiro e São Paulo: Banco Mundial, Editora Campus, Editora Elsevier 2010

STEVENS, G. V. G. Politics, economics and investment: explaining plant and equipment spending by U.S direct investors in Argentina, Brazil and Mexico. International Finance Discussion Paper, Board of Governors of the Federal Reserve System, n. 490, dez. 1994 
UTHOFF, B; TITELMAN, D. K. “The relationship between foreign and national savings under financial liberalization”. In: FFRENCH-DAVIS; REISEN, D. (Orgs.) Capital flows and investment performance: lessons from Latin America. Paris: OECD, 1998, p. 23-41.

VERNON, R. International investment and international trade in the product cycle. Quarterly Journal of Economics, v. 80, n. 2, p. 190-207, mai. 1966.

VERNON, R.The product cycle hypothesis in a new international environment. Oxford Book of Economics and Statistic, v. 41, n. 4, p. 255-267, nov. 1979. 